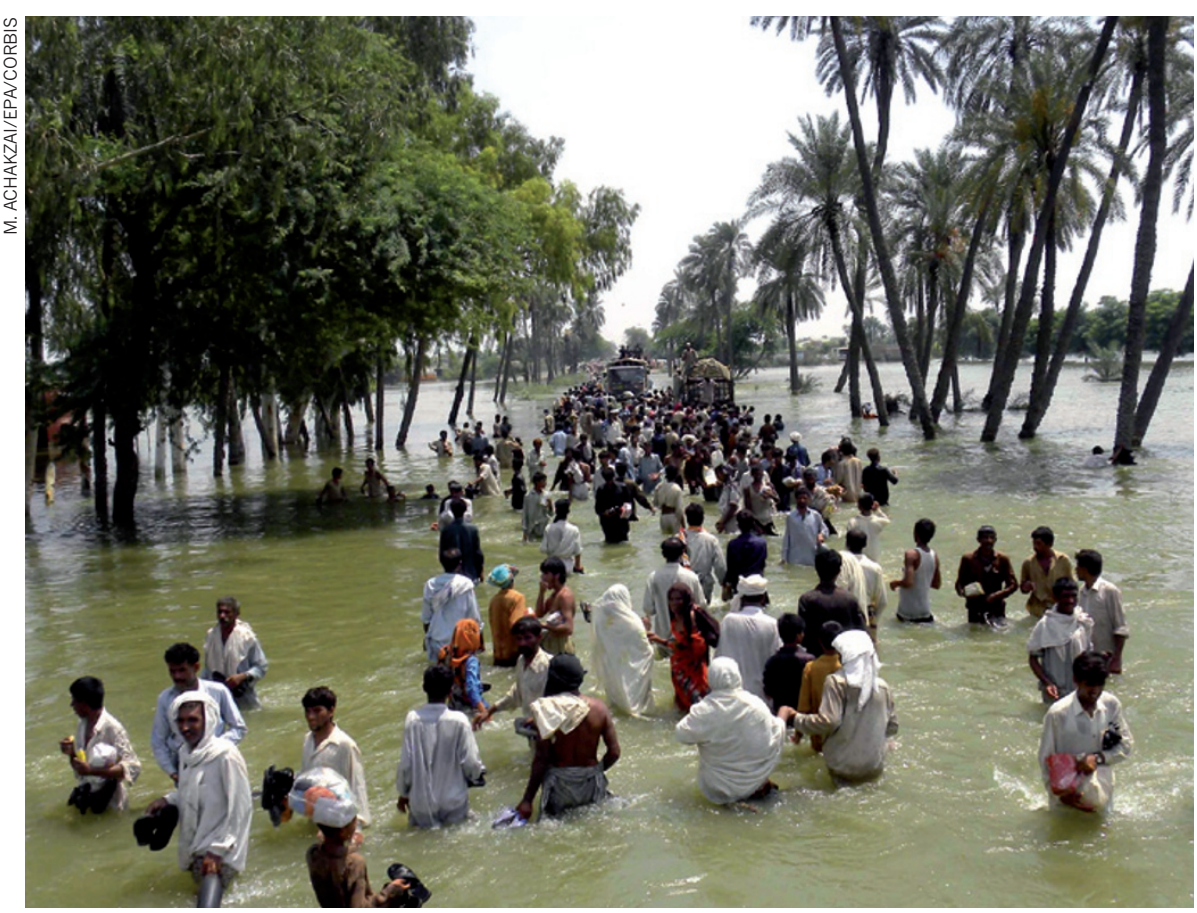

Epidemics can arise in the wake of extreme weather events such as the 2010 floods in Pakistan.

CLIMATE CHANGE

\title{
A dose of reality
}

\section{Tony McMichael welcomes an overview of an under- recognized climate issue: the threat to human health.}

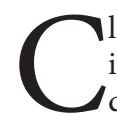

limate change may be an overarching issue of our times, yet most public debate about its consequences borders on the myopic. The long view - that human-induced global warming endangers Earth's basic life-support systems and, ultimately, people's well-being, health and survival - is obscured by more immediate preoccupations with its effects on electricity prices, gross domestic product and iconic ecosystems such as coral reefs and Arctic wildlife.

In Changing Planet, Changing Health, physician and public-health expert Paul Epstein and science journalist Dan Ferber explore far-reaching issues around climate and human health. The book covers the direct and indirect impacts of climate change on infectious diseases, food yields and nutrition, freshwater flows, air quality and the health consequences of community hardship and lost livelihoods. Epstein is a pioneer in this field, one of a handful of medical graduates who, in the early 1990s, focused on the emerging links between climate change and human health. Now associate director of Harvard Medical School's Center for Health and the Global Environment, he feeds into the book decades of field work, learning, teaching, research and advocacy.

Epstein opens with a personalized account of his grounding in environment and health - a semi-autobiographical leavening that recurs in several later chapters. In 1976, working in public health in post-independence Mozambique, Epstein quickly saw how the interplay of environmental, social, economic and political factors determines patterns of disease in communities. His recognition of the ecological basis of health problems, particularly infectious diseases, led him to apply the ideas of systems theory to this area, including the risks of infection in animals and plants in disturbed ecosystems.

In an excellent exposition, he discusses environmental microbiologist Rita Colwell's discovery in the 1990s of how algal blooms in warm waters nurture cholera bacteria, which then enter the marine food chain and, eventually, human consumers. This idea of an aquatic ecosystem as a culture medium for cholera bacteria, hosted by algae that proliferate in waters enriched by run-off nutrients and warming, has extended our understanding of cholera transmission well beyond the mechanistic person-to-person spread by faecal contamination.

The authors provide well-chosen historical illustrations of the social, economic and political triggers of infectious-disease outbreaks. Surprisingly, they do not mention other evidence for specific climatic influences on disease. The book attributes epidemics of bubonic plague in Europe in the sixth and fourteenth centuries and typhus in Silesia in the nineteenth century to combinations of political decline, social unrest, economic exploitation and poverty. Yet there is evidence that many such epidemics arose in the wake of regional climatic fluctuations. For example, major outbreaks of bubonic plague followed weather-driven increases in the number and activity of rodent hosts and flea vectors. Extremes of cold and wet may have increased the susceptibility of Silesian workers to typhus.

The book's main focus is the risk to human health from current and future climate change. The expectation, corroborated by some emerging evidence, is that humaninduced climate change will expose populations to more intense floods, storms and fires; more severe heatwaves; and changes in the rates and ranges of infectious diseases, which will encroach or increase in many regions, yet decrease in others. It is also likely to impair global crop yields (but with regional variability), and disrupt societies and their health through displacement, regional setbacks in farm yields and rural family incomes.

The authors discuss the still-debated relationship between climate change and malaria; how future climate-change scenarios may affect patterns of dengue fever, Rift Valley fever and other infectious diseases; and the risks of respiratory diseases from climaterelated increases in air pollution.

They also examine the adverse effects of climate on food supplies, nutrition and child survival, particularly in populations that have low food security; as well as the detrimental impacts of ocean warming, increased acidity and other environmental shifts on marine ecosystems, fish harvests and toxins in seafood. They consider climate effects on forest ecosystems and biodiversity, such as increased beetle infestations in US pine forests and the subsequent forest-fire risks of dead trees, and the susceptibility of poor and vulnerable communities to injury, death and disease from extreme

\section{$\rightarrow$ NATURE.COM}

For more on malaria control, see: go.nature.com/p8rhen 
weather events. Epstein and Ferber conclude by exploring solutions. In their own guardedly optimistic words, they aim to show "how we must transform the way we power society and organize our economy to preserve a liveable planet. But it is also about the incredible opportunities that will arise once we do."

They examine the political and cultural impediments to climate-change acceptance and policy response in the United States. Technological options for achieving a low-carbon economy are detailed, including the relative risks and benefits of alternative energy sources. The biggest challenge, they say, will be to modify consumption behaviours and expectations. Yet many benefits beckon as societies undertake transformative technological and behavioural actions to abate climate change. Localized health gains would result - such as breathing cleaner air if fewer fossil fuels were burnt, and having healthier bodies if we relied less on cars.

They boldly explore possibilities for transforming the global economic system, including the creation of a new international financial architecture to replace the current outmoded system. Inequalities in power and profit in current worldwide trade need to be remedied, and greater weight must be given to achieving international equity, population well-being and environmental sustainability. Although the authors recognize the merits of market-based economies, they argue that the prevailing model is inadequately regulated and increasingly damaging in a world where commodities and capital flow across national borders, often to the disadvantage of poorer countries.

The authors emphasize that the great challenge for the world community given the climate threat to the future of our species and to those we depend on is to build and benefit from a sustainable set of social values, economic priorities, low-impact technologies and coordinated national and international institutions. We urgently need to comprehend that the risks to human health and populations will be great if climate change continues on its current trajectory. Because human health is 'the bottom line' at which the many adverse consequences of climate change will converge, Changing Planet, Changing Health is an excellent corrective for climate-change myopia.

Tony McMichael is a professor at the National Centre for Epidemiology and Population Health at the Australian National University, Canberra, Australia. e-mail:tony.mcmichael@anu.edu.au

\section{Grime and punishment}

\section{Daniel Cressey finds there is more to dirt than disease} at a London exhibition.

$\mathrm{O}$ f more than a dozen exhibitions held at London's Wellcome Collection in the four years since it opened, curator Kate Forde admits that this is the first on which she has consulted the gallery's cleaners.

Dirt attempts to make visitors think again about mundane muck. The exhibition takes inspiration from the ideas of anthropologist Mary Douglas, who noted that what we consider to be dirt is based on context - a theme that is explored in six cities around the world and across human history. Accompanying events include conversations with a street sweeper and with the wonderfully titled 'chief flusher' of local utility firm Thames Water.

Starting in the Netherlands in the seventeenth century, the displayed pottery, tiles and engravings show the 'cleanliness is next to godliness' obsession of the Delft Christians in their spotless homes. We encounter favourites of science historians: one of Antonie van Leeuwenhoek's surviving microscopes sits alongside a copy of Robert Hooke's Micrographia with its drawings of microbes. Van Leeuwenhoek's description of the tiny 'animalcules' found in dirty water revealed the creatures previously hidden in the grime.

The health theme continues to unfold through the squalor of Victorian times, with

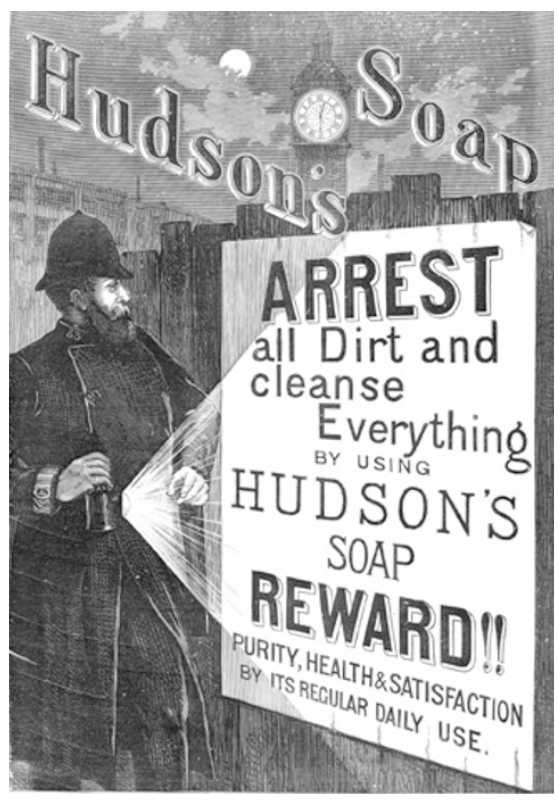

Dirtiness can have social implications.

\author{
Dirt: The Filthy \\ Reality of \\ Everyday Life \\ The Wellcome \\ Collection, London. \\ Until 31 August 2011
}

septics in Glasgow. But
things soon take a darker turn as the show moves on to reveal how ideas of cleanliness were co-opted for the oppression of those who were considered dirty.

A 1911 exhibition on hygiene in Dresden, Germany, is the starting point for the fourth cityscape. The chilling quote from the country's Law for the Prevention of Genetically Diseased Offspring from the 1930s hints at where this cleanliness obsession is headed: "Eradicate biologically inferior hereditary taints. Promote a gradual cleansing of the nation's ethnic body."

The exploration of the use of the word 'dirty' continues with the section on the people who clean the latrines of New Delhi and Kolkata, and their lowly place as 'untouchables' in India's caste system. Here is placed the most deliberately provocative of the modern art pieces displayed alongside the historical works throughout the show: several large grey slabs that make up the 'Anthropometric Modules' constructed from human faeces, by artist Santiago Sierra.

Most of the artworks are blunt in carrying Douglas's message that dirt is not bad, simply contextual. Angela Palmer's indistinguishable air samples, collected in 2007 from the cleanest and most polluted sites in the world, make invisible again what van Leeuwenhoek strove to make visible. Serena Korda’s bricks - made with dust collected from locations ranging from J. G. Ballard's books to the UK House of Commons debating chamber transform the dirt by giving it utility.

The most powerful proof that dirt is 'matter out of place' and can be redeemed by repositioning it is found at the end of the exhibition. Here the show moves forward in time, to New York's Staten Island in 2030. By then, it is hoped that Fresh Kills, one of the world's largest waste-dumping sites, will have been transformed into an urban park.

With exhibits such as a carpet made of dust, Dirt also generates what it celebrates. So it is a good job that the gallery's cleaners are on board. 